\title{
COMPARISON OF INTERIOR CRASHWORTHINESS OBSERVED IN PASSENGER TRAIN ACCIDENTS AND 8G DYNAMIC SEAT SLED TESTS
}

\author{
Kristine Severson \\ David Tyrell \\ Volpe National Transportation Systems Center \\ Cambridge, MA, USA
}

\section{ABSTRACT}

The Office of Research and Development of the Federal Railroad Administration conducts engineering research to address protection of passengers and crew during train accidents. This research includes accident investigations and dynamic seat testing to assess occupant injury during simulated accident conditions.

Observations from selected accident investigations are compared with dynamic seat test results, based on the requirements in the Standard for Passenger Seats in Passenger Rail Cars, APTA-SS-C\&S-99-016 [1], referred to simply as the Seat Standard. The Seat Standard requires sled testing of rail passenger seats to demonstrate that seats provide a minimum level of crashworthiness in the event of an accident.

The interior crashworthiness comparisons between accidents and seat tests are based on the deceleration time history (crash pulse), damage to seats and/or tables, injury type and severity, and occupant kinematics. These comparisons have been made to assess the degree to which current test practice produces injury measurements and interior fixture damage that are consistent with the injuries and equipment damage observed in accidents. When test results and accident observations do not compare well, revisions to the prescribed test conditions may be warranted.

The following three accidents have been selected for comparison in this paper. They were selected from accident investigations in which the Volpe National Transportation Systems Center participated, the amount of relevant data collected during the investigation, and the dynamic seat test data that was available for comparison of the specific type of seats or tables involved in the accidents. The accidents represent a range of accident speeds, type of equipment, and collision severity:

- passenger train to freight train collision with a closing speed of $80 \mathrm{mph}$ in Chatsworth, California, on September 12,2008 [2]
- passenger train to freight train collision with a closing speed of $33 \mathrm{mph}$ in Chicago, Illinois, on November 30, $2007[3,4]$

- passenger train to freight car collision with a closing speed of $23 \mathrm{mph}$ in Canton, Massachusetts, on March 25, 2008.

A companion paper provides detail on the structural crashworthiness of the cars in the same three accidents, and describes the computer models that were developed to estimate the crash pulse, or acceleration-time history, for each rail car in the accidents [5].

\section{INTRODUCTION}

The Office of Research and Development of the Federal Railroad Administration conducts engineering research to address protection of passengers and crew during train accidents. As illustrated in Figure 1, this research has four components:

1. Train accidents are investigated to estimate the causal mechanisms of injury and fatality.

2. Collision scenarios, simplified from accident conditions, are developed and analyzed.

3. Alternative strategies to improve occupant protection and reduce the potential for injury are developed.

4. Conventional and improved component designs are tested, and the results compared to quantify the potential improvement.

In collaboration with industry, the results of the research are applied to develop industry safety standards and FRA regulations. Improved equipment is designed according to the evolving standards, and introduced into service. These components constitute an evolutionary cycle, in which continuous research leads to constantly improving standards and designs.

This material is declared a work of the U.S. Government and is not subject to copyright protection in the United States. Approved for public release; distribution is unlimited. 


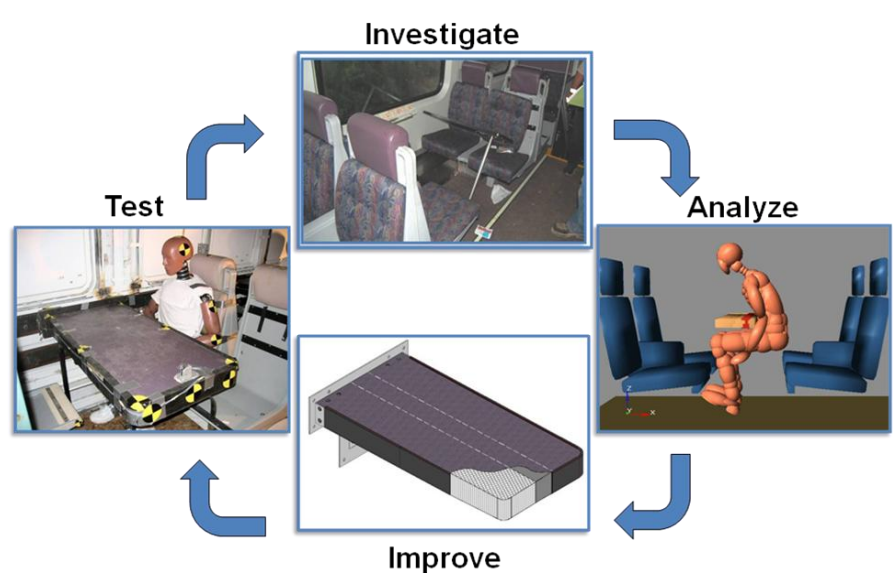

FIGURE 1. CYCLE OF ENGINEERING RESEARCH ON INTERIOR OCCUPANT PROTECTION

The next sections of this paper describe the steps of an accident investigation, the interior dynamics during an accident or test, and dynamic seat testing. The remainder of the paper focuses on the comparison of interior crashworthiness observed in accident investigations and in seat testing.

\section{ACCIDENT INVESTIGATIONS}

The Volpe Center investigates train accidents as part of the FRA forensic investigation team. The Volpe Center has participated in about fifteen accident investigations since 1999. The primary objective of the forensic team is to estimate the sequence of events and determine the causal mechanisms of injuries and fatalities. A secondary objective of the accident investigations is to gather and compare accident data with test data, to ensure that future testing is representative of actual accidents. The team gathers and organizes information needed to evaluate the effectiveness of current crashworthiness and emergency preparedness regulations and to develop future regulations and safety standards.

The first phase of an accident investigation is conducted at the scene of the accident. Investigators travel to the site of the accident as soon as possible, usually within 24 hours of the accident. Damage to the interior and exterior car structures and the wayside is documented. Hospitals that admitted accident victims are visited and interviews are conducted with as many passengers as possible. Forensic information gathered from the cars is combined with information from passenger interviews, first responder interviews, and medical and autopsy reports to estimate the causal mechanisms of injury.

The second phase of the investigation is to analyze the data collected on-site, including real-time operational data from the train's data event recorder, to develop computer simulations. Collision dynamics models can be created based on the initial accident conditions, event recorder data, force-crush data measured during full-scale impact tests, where applicable, and measured vehicle crush and displacement data post impact. These models can assist in the evaluation of interior crashworthiness and guide potential improvements.

\section{INTERIOR COLLISION DYNAMICS}

Collision dynamics models can be used to estimate the acceleration-time histories of each rail car, which can be integrated to create a plot of relative velocity vs. relative displacement, also referred to as secondary impact velocity, or SIV. The SIV curves can be used to compare the severity of different conditions, such as an actual accident and a sled test using an 8G, $250 \mathrm{~ms}$ triangular crash pulse. An SIV curve provides a rough estimate of the impact velocity for a secondary impact, i.e., the impact between an occupant and some part of the interior, usually a seat or table or bulkhead. The SIV generally increases with distance traveled by the occupant within the car, prior to secondary impact. As an example, the curve in Figure 2 represents the idealized relative velocity of an occupant in free-flight against its relative displacement with respect to the car interior, based on the sled acceleration during a typical $8 \mathrm{G}$ sled test.

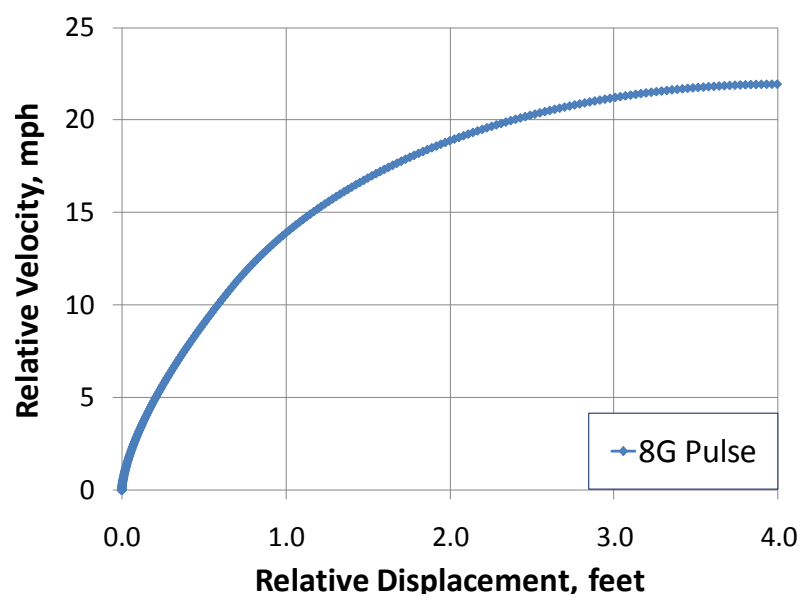

FIGURE 2. PLOT OF SECONDARY IMPACT VELOCITY (SIV)

The SIV can be estimated by locating the relative displacement on the curve that is associated with a given seating configuration. The SIV can be minimized by judiciously positioning compliant seats, tables, and bulkheads to arrest the occupant before large relative velocities are attained, or by positioning seats to face opposite the direction of travel, especially in cars that are positioned at the ends of the train, which tend to experience the highest accelerations since they are the first cars to be impacted.

The two primary factors that influence the severity of the secondary impact are the SIV and the stiffness of the impacted object. Occupant kinematics may also influence the injury type and severity. For example, a low-speed secondary impact with a very stiff, low-back seat can inflict serious injury due to impact forces and lack of compartmentalization. In contrast, a high-speed secondary impact with a high-back, moderately stiff, deformable seat would likely result in less severe injuries.

SIV curves provide a useful means of comparing different acceleration-time histories, or crash pulses, which usually

This material is declared a work of the U.S. Government and is not subject to copyright protection in the United States. Approved for public release; distribution is unlimited. 
consist of high-frequency oscillations that make them difficult to compare. The crash pulse in an accident is principally based on the impact speed and mass and stiffness of the rail vehicles. Which accidents may produce the most severe vehicle accelerations is not always intuitive. The crash pulse generally does not increase linearly with the impact velocity of a train collision. For example, accidents in which there is significant car crush caused by a large initial velocity or a relatively low crippling load may have a less severe crash pulse. In contrast, accidents with a moderate impact speed or a relatively large force required to compromise structural integrity, resulting in minimal car crush, will likely result in a more severe crash pulse.

\section{SLED TESTING DESCRIPTION}

The Volpe Center first started to conduct sled tests in support of the FRA in 1994. This testing led to the development of the original Seat Standard in 1999. The test set-up has not varied much in the 15 years of sled testing passenger rail seats. Two rows of seats are attached to a rigid test sled in the same manner that they are attached to rail cars, using the predominant seat pitch that is used in service. Sometimes load cells are placed at the point of connection to the test sled to measure the attachment loads during the test. The anthropomorphic test devices (ATDs) are positioned in the rear row of seats, one ATD per seat position. The test sled is accelerated according to a prescribed pulse, usually an $8 \mathrm{G}, 250$ ms pulse, as specified in the Seat Standard, and shown in Figure 3. For seat qualification testing, all ATDs are instrumented with triaxial head and chest accelerometers, and neck and femur load transducers. Video cameras from multiple positions are used to document the test results. Pre- and posttest photos are also taken.

The objectives of the sled tests are to demonstrate that:

1. All seat components remain attached.

2. ATDs remain compartmentalized between the two rows of seats.

3. Occupant injury criteria are below maximum allowable levels.

The American Public Transportation Association (APTA) seat safety standard, APTA-SS-C\&S-016 [1], to which passenger seats must be tested, was based upon the above general description of sled testing. It has been revised twice since it was originally issued. Some changes were made for clarification and to incorporate more detail on how to satisfy the seat attachment requirements in the Federal Regulations. Other significant changes included the addition of neck injury criteria, a requirement to instrument the ATDs in the rearfacing sled test, and results from occupant experiments in fullscale equipment tests for informational purposes. Such changes are often the result of Government-sponsored research as described in this paper.

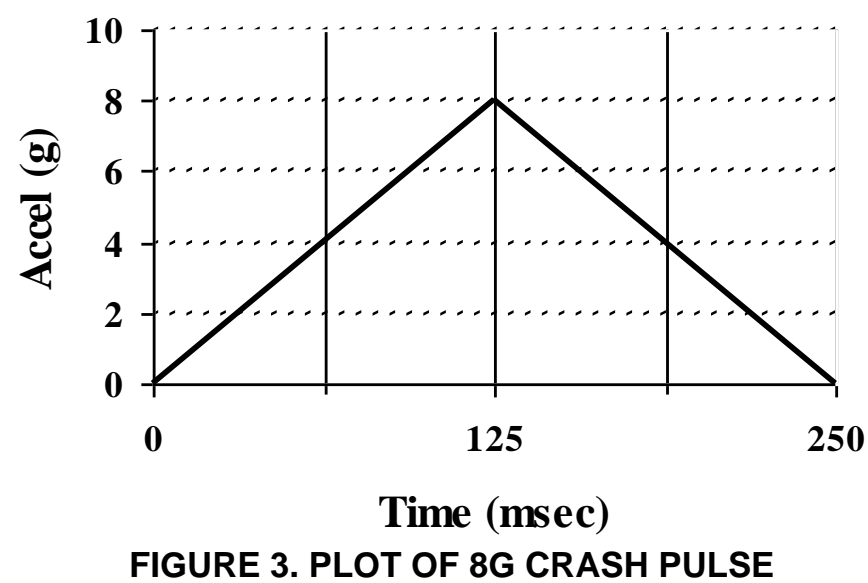

\section{COMPARISON OF ACCIDENT INVESTIGATION DATA AND SLED TEST RESULTS}

\section{Chatsworth, CA, September 12, 2008}

The first accident to be compared with sled test data occurred in the Chatsworth District of Los Angeles, CA, at 4:22 pm on Friday, September 12, 2008. This accident involved westbound, locomotive-led Metrolink passenger train \#111, and eastbound, locomotive-led Union Pacific (UP) LOF65-12 freight train. Each train was traveling at approximately $40 \mathrm{mph}$ at the time of impact, resulting in an 80-mph closing speed. The Metrolink train consisted of a locomotive, followed by two coach cars and a trailing cab car. The UP freight train was led by two locomotives, followed by 17 loaded freight cars. A schematic depiction of the initial impact is shown in Figure 4 below.

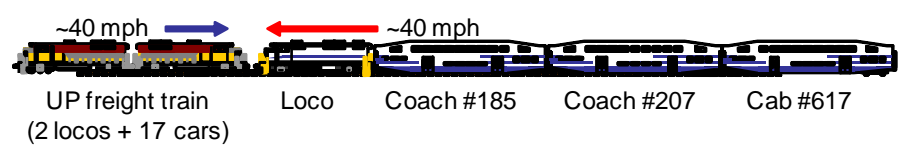

\section{FIGURE 4. SCHEMATIC OF INITIAL CONDITIONS IN CHATSWORTH ACCIDENT}

The passenger locomotive and the accumulated crushed material of Car \#185 penetrated nearly 65 feet into the passenger volume of Car \#185 in a telescoping action, or about $3 / 4$ of the total car length. More detailed information about this accident can be found in Reference 2 .

The Metrolink train has seating capacity for about 437 passengers. According to the Metrolink conductor onboard the train, 165 passengers were estimated to be on the train at the time of the accident.

Following the accident, a lumped-mass collision dynamics model was developed to estimate the gross motions (of the passenger cars) resulting from the accident. Model input data was based on test data from similar equipment [6] and data gathered at the scene of the accident. The acceleration time history for each car was integrated to produce a plot of relative

This material is declared a work of the U.S. Government and is not subject to copyright protection in the United States. Approved for public release; distribution is unlimited. 
velocity vs. relative displacement. The resulting curves are shown below in Figure 5, along with the corresponding plot for the $8 \mathrm{G}$ sled test crash pulse for comparison. The $8 \mathrm{G}$ pulse was initially based on a computer model of locomotive-led trains colliding at $70 \mathrm{mph}$, which is very similar to the accident conditions in Chatsworth [7].

The SIV plots for the first two passenger cars are very close to that of the $8 \mathrm{G}$ pulse. The SIV plot for the trailing cab car is more severe than the $8 \mathrm{G}$ pulse. The trailing car in a consist can experience a higher deceleration than the preceding car because there is no trailing car to push it forward. The increased level of interior damage in the trailing cab car compared to the second coach car and the uncrushed portion of the first coach car supports this theory.

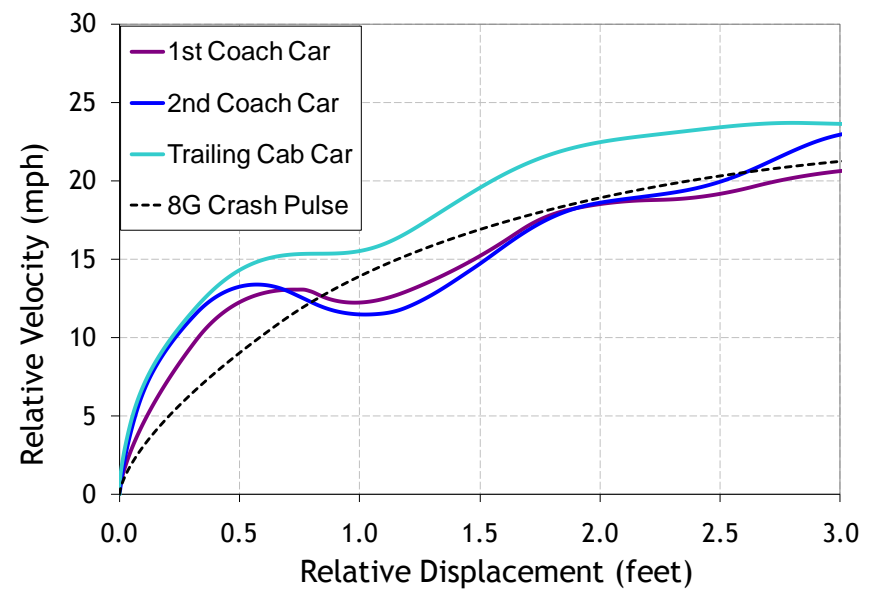

\section{FIGURE 5. PLOTS OF ESTIMATED SECONDARY IMPACT VELOCITY (SIV) FOR CHATSWORTH}

\section{Summary of Seat/Table Damage in Chatsworth}

The seating in the Metrolink cars consisted primarily of transverse, two-passenger seats, with an aluminum seat base and one-piece fiber-reinforced thermoplastic seats with cushions. The seats are relatively stiff compared to other commuter seats. The workstation tables consisted of a plywood table top covered in melamine, and supported by a vertical stainless steel pedestal and a wall-mounted bracket. The tables were also relatively stiff. The damage to the interior fixtures, such as seats, tables, bulkheads, stanchions, etc. on the Metrolink train is described by car in Table 1 below. The Velcro fasteners that attached the seat cushions to the seats detached in several locations.

The two coach cars in the Chatsworth accident were delivered in 2001-2002; the cab car was delivered in 1992. The technical specifications for these cars were developed years before the cars were delivered (prior to the authorization of the Seat Standard); therefore the seats in these cars were not required to meet the requirements in the Seat Standard.

The information in Table 1 indicates that the trailing cab car \#617 incurred the most damage to interior fixtures. The increased damage in the cab car could have been the result of higher occupancy in that car, but more likely it was the result of the increased deceleration of the cab car, resulting in secondary impact velocities which are $20-25 \%$ higher in the cab car than in the first two coach cars, as shown in the SIV curve in Figure 5.

TABLE 1. INTERIOR DAMAGE TO METROLINK CARS

\begin{tabular}{|l|c|c|c|}
\hline Interior Damage Grab & $\begin{array}{c}\text { Coach } \\
\mathbf{1 8 5}\end{array}$ & $\begin{array}{c}\text { Coach } \\
\mathbf{2 0 7}\end{array}$ & $\begin{array}{c}\text { Cab } \\
\mathbf{6 1 7}\end{array}$ \\
\hline $\begin{array}{l}\text { Cracked/Broken } \\
\text { Handles }\end{array}$ & & 6 & 11 \\
\hline Cracked Head Rests & & 2 & 2 \\
\hline Detached Head Rests & 2 & 3 & 7 \\
\hline Cracked Seat Backs & & & 2 \\
\hline Cracked Seat Pans & & & 1 \\
\hline Cracked Pedestals & & 2 & 1 \\
\hline Dislodged Tables & & 1 & 2 \\
\hline Detached Tables & & 1 & 5 \\
\hline Cracked Arm Rests & & & 4 \\
\hline Cracked Bulkheads & 2 & 1 & 2 \\
\hline Detached Stanchions & 107 & & \\
\hline Seats Crushed or Missing & 113 & 18 & 39 \\
\hline Sum of Damaged Components & & & \\
\hline
\end{tabular}

\section{Summary of Seat/Table Damage in Facing- Seat Sled Tests}

Sled tests were conducted in October, 2000, using the same type of seats that were in the Metrolink cars involved in the Chatsworth accident. The tests were intended to evaluate the seat crashworthiness in accordance with the newly approved APTA Seat Standard, and to serve as a baseline of existing seat behavior under collision conditions. A detailed report has previously been published on the facing-seat sled tests [8] but key details are summarized here to compare the seat damage between the accident and the sled tests.

Four tests were conducted using a facing-seat configuration. Two ATDs were positioned in forward-facing seats, impacting the opposing seat pair during the test. Three of these tests were conducted with an $8 \mathrm{G}$ triangular crash pulse, while one test used a $9 \mathrm{G}$ crash pulse, based on results of parametric modeling analyses [8]. One of the $8 \mathrm{G}$ sled tests also incorporated a workstation table between the facing seat pairs. Three out of four tests used two instrumented $50^{\text {th }}$ percentile male ATDs, while one test used a $95^{\text {th }}$ percentile male and a $5^{\text {th }}$ percentile female ATD. The seat pitch between facing seats was 65 inches, which is the same seat pitch used between facing seats in the Metrolink cars. See Figure 6 for a photo of the test configuration.

This material is declared a work of the U.S. Government and is not subject to copyright protection in the United States. Approved for public release; distribution is unlimited. 


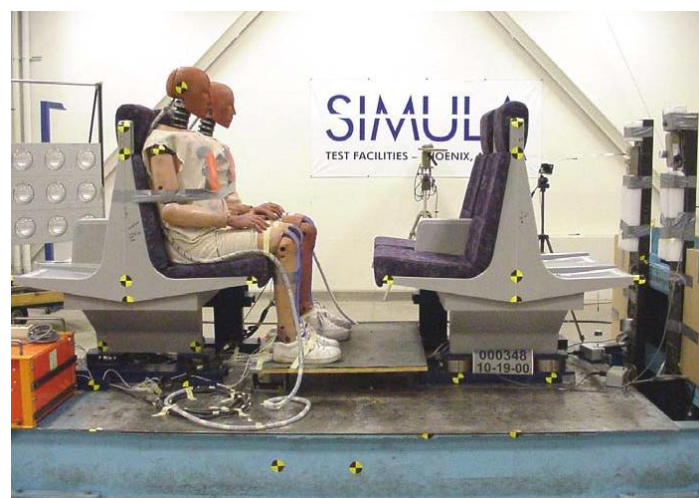

FIGURE 6. PHOTO OF TEST SET-UP

The sled tests demonstrated that the seats did not meet the injury criteria or compartmentalization requirements specified in the Seat Standard. In two of the three tests without a table, the aisle-side head rest completely separated from the seat back. In the test with the $5^{\text {th }}$ - and $95^{\text {th }}$ percentile ATDs, the window-side head rest of the facing seat failed completely due to the impact from the larger ATD. In some tests, the grab handles on the head rest cracked, but the head rest did not detach from the seat back. These types of seat damage were also prevalent in the Chatsworth accident.

In the single test with a table between the facing seats, the two $50^{\text {th }}$ percentile ATDs impacted the table, causing it to shear off at the wall attachment, which led to a failure at the floor attachment as well.

The cushions were attached to the seat frames with Velcro. They remained attached in all but one test, which was the test with the higher crash pulse. Several seat cushions detached during the accident as well, indicating that the cars may have experienced more severe decelerations than the $8 \mathrm{G}$ pulse.

Both the launch seat and the impacted seat remained attached to the wall and floor mounts in all tests. In the Chatsworth accident, all seats remained attached to the wall and floor mounts as well.

Photographs comparing the similarities in interior damage between the accident and the test are shown in Figure 7.

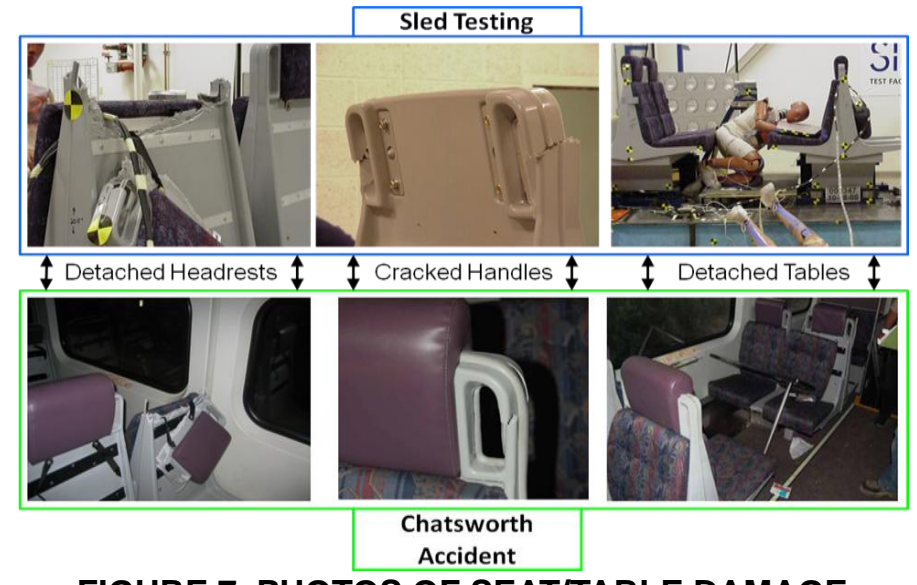

FIGURE 7. PHOTOS OF SEAT/TABLE DAMAGE

\section{Summary of Injuries/Fatalities in Chatsworth}

Based on medical reports, approximately 135 injured passengers and train crew were treated at the scene of the accident. Over 100 of these people were taken to local hospitals (of which about 40 were transported via helicopter) with injuries ranging from minor to life-threatening. Injuries and fatalities to train occupants can be attributed to one of two main causes - lack of sufficient survival space or secondary impacts. It appears that 23 of the 25 fatalities were most likely due to loss of adequate survival space, caused by massive structural crush of the leading coach car \#185, according to autopsy reports. Two fatalities occurred in car \#207, likely due to inadequate compartmentalization, which generally leads to higher secondary impact velocities and more hostile impact surfaces. One passenger came to rest on the stairs leading up to the forward mezzanine, suffering fatal injuries likely caused by impact with the steps. Open seating areas with unrestricted travel between seats and rigid objects, such as stairs, are particularly hazardous. Another passenger died at the hospital after suffering severe injuries from secondary impact with an unknown object.

While most of the fatalities were caused by car crush, most of the non-fatal injuries were caused by secondary impacts with the interior. The Volpe investigators were unable to obtain the medical records from this accident due legal obstacles and associated costs, but according to the NTSB accident report [2], 25 passengers had serious injuries, defined as requiring hospitalization over 48 hours, or non-trivial bone fractures, or internal organ injuries.

Twelve passengers were interviewed in local hospitals and four emergency responders were interviewed at the scene of the accident in the days immediately following the accident. The most common injuries among the interviewed passengers with serious injuries were fractures to the vertebrae, ribs, sternums, and legs, lacerations and contusions to internal organs, concussions, and external lacerations and contusions.

Two interviewed passengers seated at tables each reported multiple rib fractures and bruised or lacerated internal organs. Two passengers, who were initially seated in facing seats (facing the direction of travel), reported that they were launched over the facing seat pair, thus not compartmentalized. One of these passengers suffered from fractured vertebrae, ribs, and a slight concussion. The other passenger had a fractured tibia, fibula, humerus, and rib. Another passenger, who was seated on a flip down seat facing a bulkhead 10 feet away, reportedly impacted the bulkhead and sustained four fractured ribs, four fractured vertebrae, and a fractured tibia. Yet another passenger was seated on a side-facing bench seat, impacted a bulkhead/partition, and suffered from fractured ribs, clavicle, scapula, and arm, a punctured lung, and a lacerated liver. Without access to detailed medical records, a comprehensive list of specific injuries and corresponding severity could not be developed.

During passenger interviews it was learned that several passengers were not compartmentalized between adjacent rows

This material is declared a work of the U.S. Government and is not subject to copyright protection in the United States. Approved for public release; distribution is unlimited. 
of seats. In fact, several passengers were launched from their original seats (likely due to a combination of the relatively low seatback height and the pitching motion of the cars), coming to rest as far as 25 feet forward of their original positions. One rear-facing passenger seated at the midpoint of the upper level of car \#617 described finding his friend, along with about six other people, in a pile at the bottom of the stairs leading down to the forward mezzanine. Presumably, the other people had also been seated at the time of the accident. These passengers were clearly not compartmentalized between rows of seats.

As observed in full-scale impact tests, cars tend to exhibit a pitching motion during collisions. The leading end of the car dips down, while the trailing end of the car rises up. This pitching motion exacerbates compartmentalization issues, increasing the likelihood that occupants may travel over the top of low seat backs. The damage to the car couplers indicates that the passenger cars likely experienced a pitching motion during the accident, inducing vertical car body accelerations that may have increased the propensity of passengers to override the tops of seat backs in the accident.

\section{Summary of Injury Measurements in Facing- Seat Sled Tests}

The anthropomorphic test devices (ATDs) in the sled tests were instrumented to measure head and chest acceleration, and femur and neck loads. These measurements were used to calculate the following injury criteria: head injury criterion (HIC), chest deceleration, axial femur load, neck shear load, neck flexion/extension moment, axial neck tension/compression, and neck injury (Nij). Only the first three criteria listed above were required in the original APTA Seat Standard. Revision 2 of the Seat Standard, issued in 2010, includes requirements for the four additional criteria related to neck injury that are consistent with the neck injury criteria specified by the National Highway Transportation Safety Administration in the Federal Motor Vehicle Safety Standards (FMVSS) for automobiles [9].

In the sled tests, the measured HIC, 3ms chest deceleration, and axial femur loads were all below the human injury criteria specified in the original version of the APTA Seat Standard, which were 1000, 60 Gs, and 2,250 lbf, respectively. The injury levels for the head, chest, and femur injuries measured in the sled tests were consistent with Abbreviated Injury Scale (AIS) level 1, or minor injuries to the head, chest, and femur. These measurements are consistent with concussions and single rib fractures, which were also observed in the Chatsworth accident. However, there were also several head and chest injuries in Chatsworth that were classified as AIS 3 and above, indicating that the accident conditions may have been more severe than the $8 \mathrm{G}$ test conditions. Passengers seated in facing pairs of seats, with and without intervening tables, seemed to suffer most of the serious secondary impact injuries. In contrast, the passengers seated in rear-facing seats experienced minor or no injuries.

This material is declared a work of the U.S. Government and is not subject to copyright protection in the United States. Approved for public release; distribution is unlimited.
At least one ATD from each sled test exceeded at least one neck injury criterion, except in the test with a workstation table. In all four tests, at least one ATD was not compartmentalized. After the head rest failed, the ATDs typically traveled over the top of the seat back of the facing seat. The tethers that fastened the ATDs to the test sleds restricted further ATD motion that may have led to an increase in measured injury criteria. The excessive neck injury measurements are consistent with more serious injuries in the Chatsworth accident, such as multiple fractured vertebrae.

The likelihood of abdominal injuries could not be assessed during the table test because the ATDs were not equipped with abdominal sensors. However, concern was expressed over the potential for abdominal injuries, due to the impact with the table, as well as impact with the jagged edge of the facing seat back after the head rest detached. In the Chatsworth accident, interviewed passengers had suffered from internal organ injuries such as lacerations and contusions to the liver and spleen, and punctures and contusions to the lungs, caused by table impacts as well as seat impacts. Numerous external lacerations were observed in Chatsworth. This type of injury cannot be assessed by ATDs, but lacerations may have been caused by contact with the jagged surfaces of damaged seats.

The sled testing of the Metrolink seats only evaluated forward-facing ATDs in the facing-seat configuration. There are several other seating configurations in the Metrolink cars that have not been evaluated with sled testing, such as sidefacing bench seats, rear-facing seats, seats at bulkheads, seats in consecutive forward-facing rows, etc.

In the Chatsworth accident, several passengers were likely seated in rear-facing seats, a seating configuration that has been shown to provide increased protection from secondary impacts [10]. One passenger that was interviewed after the Chatsworth accident was in a rear-facing seat on the upper level of car \#617 when the accident occurred. He did not need to be treated at a hospital, suffering only with a stiff neck and back, and a headache. In the final judgment describing the legal settlement from the Chatsworth accident, it was stated that $100 \%$ of the passengers that were literally able to "walk away" from the accident were seated in rear-facing seats at the time of the accident.

Additionally, several passengers were seated in consecutive rows of forward-facing seats. Analysis of the data gathered shows that this configuration also tends to provide more protection from secondary impacts than a facing-seat configuration.

\section{Chicago, IL, Amtrak accident, November 30, 2007}

On November 30, 2007, a Norfolk Southern (NS) freight train was stopped on a main track of NS's Dearborn Division in Chicago, Illinois. A westbound Amtrak passenger train was routed to the same track and given a restricted signal. At approximately 11:30 am C.S.T., the passenger train struck the 
rear end of the freight train at a speed of approximately 33 $\mathrm{mph}$. The passenger train consisted of a leading locomotive and three coach cars. Thus, the passenger train locomotive collided with the rear of the last freight car in the freight train. A schematic depiction of the initial impact is shown in Figure 8 below.

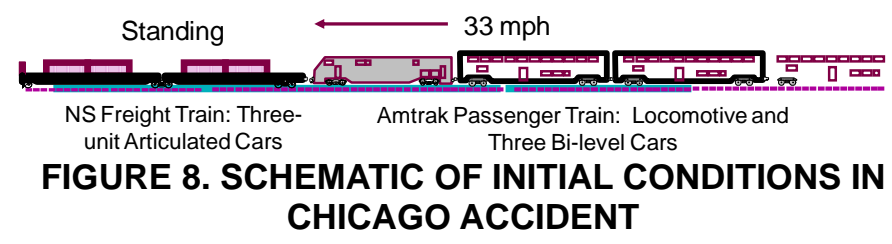

There were no fatalities caused by the accident and only minor injuries were incurred by the passengers and crew. However, the engineers located within the locomotive cab at the time of impact sustained more severe injuries than the passengers and crew located within the coach cars. This was due to the fact that the locomotive sustained most of the exterior and interior structural damage and bore the brunt of the impact, creating a situation close to life threatening within the cab. The passenger train remained in line while the locomotive crushed and overrode the freight car.

Following the accident, a lumped-mass collision dynamics model was developed to estimate the gross motions of the cars in the passenger train. The acceleration time history for each car was integrated to produce a plot of relative velocity vs. relative displacement. The resulting curves are shown below in Figure 9, along with the corresponding curves for $5 \mathrm{G}$ and $8 \mathrm{G}$, $250 \mathrm{~ms}$ crash pulses.

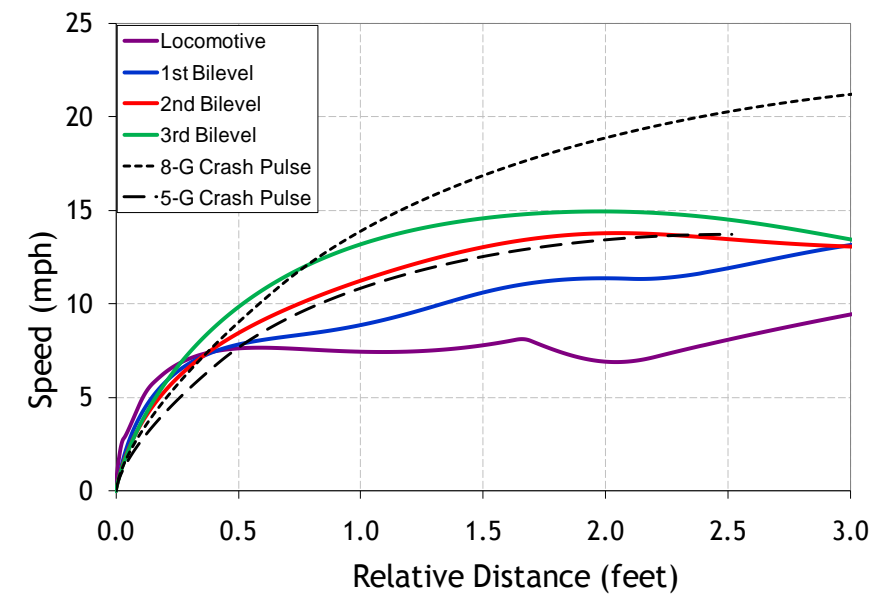

\section{FIGURE 9. PLOTS OF SECONDARY IMPACT VELOCITY (SIV) FOR CHICAGO}

\section{Summary of Seat Damage in Chicago Accident \\ The seating in the Amtrak cars consisted primarily of transverse, two-passenger seats, with a steel seat base and frame and seat back and bottom cushions. The seat pairs can be rotated $180^{\circ}$ to face either forward or backward. The seats are}

relatively compliant compared to the Metrolink commuter seats.

The damage to the coach car interiors was minor in comparison to the locomotive interior. After the accident, two seat pairs in the first coach car, four seat pairs in the middle coach car, and three seat pairs in the last coach car were all partially rotated with respect to their original positions. The seat latches had failed to secure the seat pairs in the locked position. In addition to the four rotated seat pairs, the middle coach car also had a seat pair that had separated from the wall and floor due to fastener failure.

\section{Summary of Seat Damage in Amtrak Seat Sled}

\section{Tests}

In 1995, seven sled tests were conducted on Amtrak's traditional coach seat at MGA Research Corporation in Burlington, WI [11]. The Amtrak seat tests were the first tests conducted by the Volpe Center, to evaluate the performance of seats under dynamic loading conditions. Although the APTA Seat Standard did not exist at that time, the tests were conducted in a manner consistent with the eventual Seat Standard. Two rows of two-person seats were fastened to the sled at the floor and the wall via standard seat tracks that are used in Amtrak cars, at a 52-inch seat pitch. Two ATDs were positioned in the rear seat pair; only the wall-side ATD was instrumented. See Figure 10 for photo of test set-up.

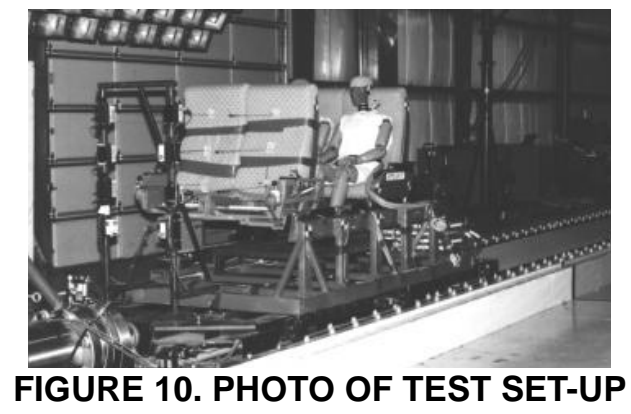

The first three tests were conducted to evaluate the influence of crash pulse on the seat performance. The test sled was accelerated using a $250 \mathrm{~ms}$ triangular crash pulse with a peak amplitude of 5,10 , and 8 Gs, respectively. The remaining tests were conducted with an $8 \mathrm{G}$ pulse to evaluate the influence of initial ATD position, i.e., placement of seat back and leg rest position.

In the $5 \mathrm{G}$ test, the ATD's secondary impact with the forward seatback remained elastic, that is, there was very little permanent deformation to the seat. There was minor deformation to the recline mechanism, which is housed inside the armrest shroud. This type of damage may have also occurred in the Chicago accident, but it went unnoticed during the investigation because the shrouds were not removed for inspection.

In the $10 \mathrm{G}$ test, there was substantial plastic deformation of the metal underframe of the forward seat pair. The floor

This material is declared a work of the U.S. Government and is not subject to copyright protection in the United States. Approved for public release; distribution is unlimited. 
track had deformed slightly under the forward seat pedestal. The seat separated from the test sled at the wall mounting, which occurred in a number of tests. The wall attachment design that was tested had a very shallow locating pin, which was able to separate from the wall track and dislodge the seat bracket with very minimal deformation. The locking mechanism for the seat rotation failed on the rear seat pair, which only had to endure the inertia of its own mass. The failure was apparently due to a cold weld.

The first $8 \mathrm{G}$ test was conducted with only one ATD in the aisle seat position to increase the load on the locking mechanism that failed in the previous test. In this test the recline mechanism of the forward aisle-side seat back failed, apparently due to a poor weld of the attachment post for the recline mechanism. The seat locking mechanism remained intact. There was virtually no permanent deformation of the forward seat frame.

The four subsequent tests were all conducted with two ATDs and an $8 \mathrm{G}$ crash pulse. The leg rest and seat recline positions were varied in these tests, though it is not obvious that the initial positions affected the outcomes. The most significant seat performance issue was the failure of the wall mounting bracket to remain fastened to the track on the side wall. The wall mounting failed on five of the seven tests, allowing the seat to rotate about the floor pedestal mounting. In two of seven tests the rotation was sufficient to separate the floor pedestal from the seat track, breaking the track in one test. The floor attachment is prone to failure only when the wall mount attachment fails, and the floor attachment is subjected to the entire load. Another common failure involved the recline mechanism. The rod fractured in two tests, and welds that fastened the rod failed in two tests.

Photographs of the detached and unintentionally rotated seats are shown in Figure 11.

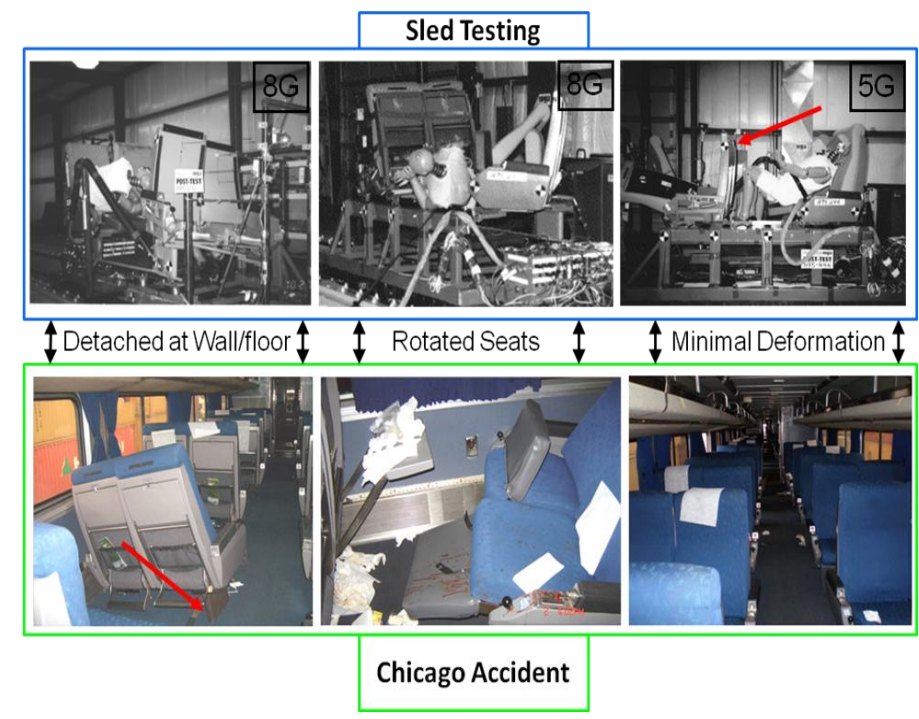

FIGURE 11. PHOTOGRAPHS OF SEAT DAMAGE

\section{Summary of Injuries in Chicago Accident}

The occupants of the Amtrak train included five crew members and 182 passengers. There were no fatalities caused by the accident and only minor injuries were incurred by the occupants. Three people were admitted to the hospital overnight, one with a shoulder fracture. It is believed that this person was standing at the time of impact. All patients were released by December 2, 2007, two days after the accident. The injuries of the passengers in the coach cars consisted mostly of bloody noses, small cuts, and bruises.

The seats performed well, given the severity of the accident. The seats were designed with a moderate amount of flexibility, i.e., they deform elastically, and in some cases plastically, to decelerate the passengers more slowly during a secondary impact, as compared to stiff, rigid seats. This subject will be described further in context with sled testing of the Amtrak traditional seats.

Further details about the interior crashworthiness of the locomotive cab and injuries sustained by the engineers can be found in another paper that is entirely devoted to the analysis of the Chicago accident [4].

The curves in Figure 9 indicate that the engineers had lower SIVs than passengers in trailing coach cars; however, they had more severe injuries. This observation highlights the point that SIV is only one factor in estimating the severity of secondary impacts. Additionally, the SIV curves presented in this paper only account for longitudinal train acceleration and do not address lateral or vertical accelerations. Longitudinal acceleration usually dominates the train motion, but lateral and vertical accelerations may be more significant factors in the event of derailment, override, and car rollover.

The strength of the impacted surface contributes significantly to the impact severity, as does sustained car body deceleration, occupant kinematics, and the specific body parts that impact the interior structure. Previously it was assumed that occupants could withstand higher car body decelerations once in contact with part of the vehicle interior. However, subsequent modeling, testing, and accident investigations have shown this assumption to be overly simplistic. For these reasons, SIV cannot be relied upon exclusively to estimate severity of secondary impacts.

\section{Summary of Injury Measurements in Amtrak}

\section{Seat Sled Tests}

The occupant injury criteria for head, chest, and femurs were within the FMVSS criteria in every test. The HIC measurements were all below 1000, the $3 \mathrm{~ms}$ chest deceleration measurement was below $60 \mathrm{Gs}$, and the peak femur loads were all below 2,250 pounds. Although neck load wasn't specified in FMVSS at the time these tests were conducted, the measured compressive axial neck loads were all below the timedependent criteria proposed at the time.

The HIC values measured in 6 out of 7 tests were below 200, which are considered to be level 1 injuries on the Abbreviated Injury Scale (AIS), or minor injuries. The highest

This material is declared a work of the U.S. Government and is not subject to copyright protection in the United States. Approved for public release; distribution is unlimited. 
HIC was 891, which is an AIS 2 injury, or moderate injury. The $3 \mathrm{~ms}$ chest decelerations were all under 20 Gs. These are all classified as AIS 1 injuries, or minor injuries. In six out of seven tests the peak femur load was below $75 \%$ of the maximum allowable load. The highest femur load measured in any test was 2,202 pounds. The 2,250 pound criterion for the peak femur load is associated with the load required to fracture the femur, which is an AIS 2 injury, or moderate.

The passenger injuries in the Chicago accident and the ATD injury measurements in all of the Amtrak seat sled tests were all classified as minor, with the exception of one moderate head injury and one moderate femur injury measured in the sled testing. These results, along with the observations of seat damage, indicate that the collision and sled test conditions are consistent.

\section{Canton, MA, MBTA Accident, March 25, 2008}

On March 25, 2008, a runaway CSX freight car impacted a stationary, locomotive-led MBTA commuter train at about 23 mph (see Figure 12). The locomotive engaged the freight car, causing dents in the front of the locomotive and one to two feet of deformation on each vehicle. The impact caused the train and the freight car to roll about 50-70 feet before coming to a stop, with the impacted vehicles still attached. The graph in Figure 13 plots the SIV curves corresponding to each car, based on results from a collision dynamics model of the accident.

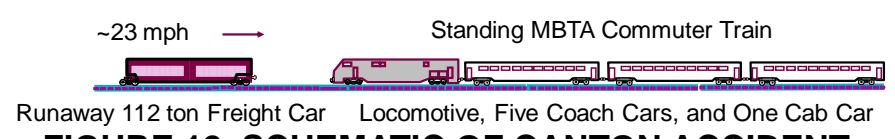

FIGURE 12. SCHEMATIC OF CANTON ACCIDENT

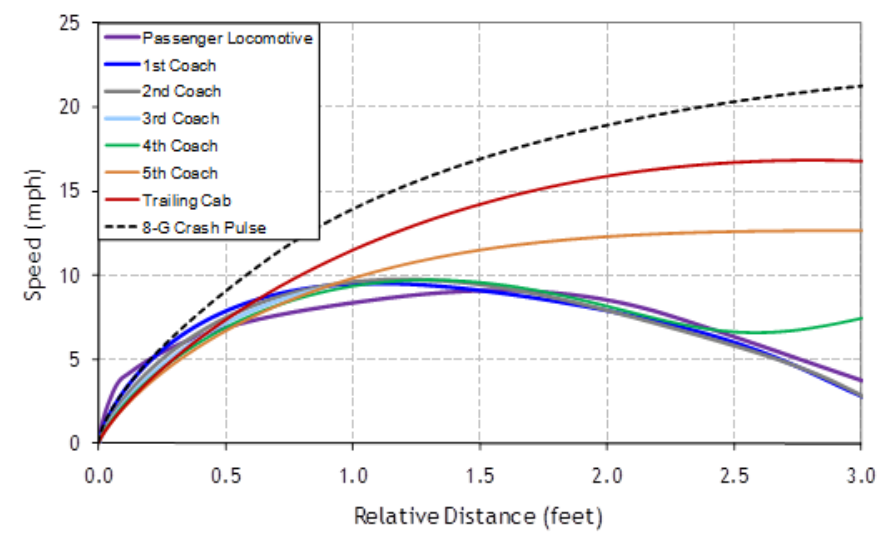

FIGURE 13. SIV PLOTS FROM CANTON ACCIDENT

\section{Summary of Seat Damage in Canton Accident}

The oldest passenger car was the first coach car behind the locomotive, car \#214. Being an older car, the car interior had been refurbished. The upgrade included improved seats that met the requirements of the ATPA Seat Standard. The other five coach cars were newer, but went into service prior to issuance of the Seat Standard. The seats in these cars had not been upgraded to meet the requirements in the Seat Standard.

All passenger cars except the cab car had M-Style seats. The M-Style seat is a fixed-position, three-passenger, traditional seat design with a tubular carbon-steel frame and a stainless steel pedestal. A thermoformed plastic base is mounted to the tubular frame and seat cushions are attached to the plastic base with clips.

The cab car contained Walkover-Style seats. The Walkover seat is a two-passenger seat with a back cushion that rotates about a pivot point to provide seated passengers with the option of changing the direction that they face in the train. The base of the seat is constructed of steel tubing, which supports the linkage mechanism used to pivot the seat back cushion forward and backward. The locking device is designed so that, in the event of a sudden stop, it engages (due to inertial force effects on the mechanism) to prevent the seat back from rotating about its pivot point. Both the M-Style and Walkover seats are relatively less stiff than the commuter seats in the Chatsworth accident.

The seats in the first coach car \#214 sustained minimal damage compared to the other passenger cars. In the second coach car \#610, 40-50\% of the seats had deformed seat brackets that fasten the seat frames to the side wall. One seat back was cracked in this car. In the third and fourth coach cars \#603 and \#651 respectively, almost $100 \%$ of the seats had deformed brackets. Two seat backs were cracked in Car \#651. In the fifth coach car \#622, 40-50\% of the seats had deformed brackets. The trailing cab car \#1523 had Walkover seats, with seat backs failing on four seat pairs. These failures resulted in steel tubes protruding through the fabric, representing a very hostile impact surface.

\section{Summary of Seat Damage in M-Style and} Walkover Seat Sled Tests

A series of $8 \mathrm{G}$ sled tests were conducted in 1998 [12]. Two sled tests used M-Style seats similar to those in the second, third, fourth, and fifth MBTA coach cars in the Canton accident. Two sled tests used three-passenger Walkover seats similar to the two-passenger Walkover seats that were in the cab car in Canton. The first test of each seat type used three $50^{\text {th }}$ percentile male ATDs. The second test of each seat type used one $95^{\text {th }}$ percentile male ATD, one $50^{\text {th }}$ percentile male ATD, and one $5^{\text {th }}$ percentile female ATD. All three ATDs in each test were instrumented. The seat pitch was 32 inches in each test.

In both sled tests of the M-Style seat, the seats stayed intact; however, all the cushions from both seats completely detached and became hazardous flying objects during the collision. The pedestal under the forward seat back deformed in each test, but did not detach from the wall or floor mounts. The damage to the seats in the tests was somewhat more severe than the damage to the seats in the accident. This observation is

This material is declared a work of the U.S. Government and is not subject to copyright protection in the United States. Approved for public release; distribution is unlimited. 
consistent with the estimated severity of the collision as compared to the $8 \mathrm{G}$ pulse used in the test.

In both tests of the Walkover seats, the seats stayed intact and the cushions remained attached. The Walkover seat back rotated forward before locking in place, thereby increasing the distance through which the occupants could travel. The same tendency for seat backs to rotate before locking was observed in the accident.

Photographs comparing the seat damage in the sled tests and the Canton accident are shown in Figure 14, for seats that were compliant with the Seat Standard and those that were not.

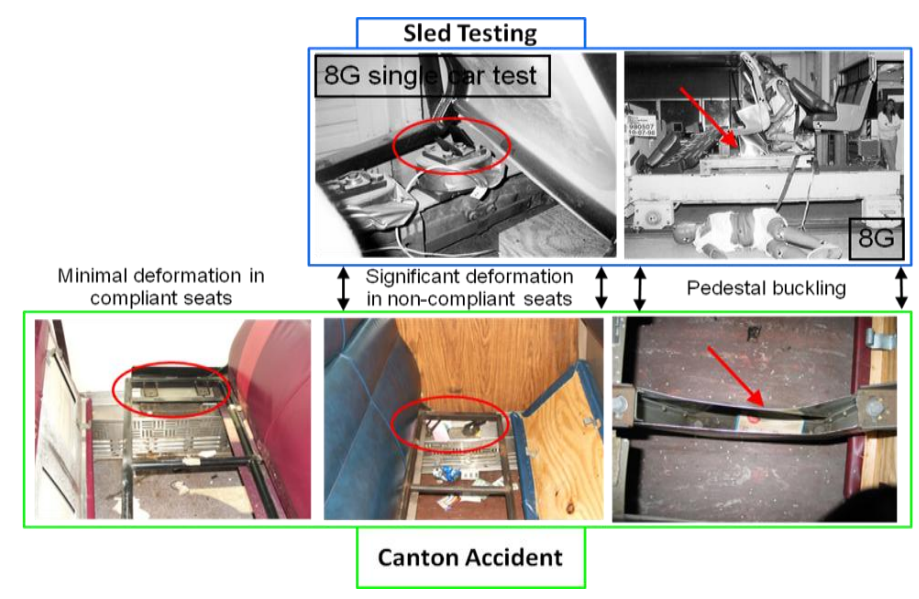

FIGURE 14. PHOTOGRAPHS OF SEAT DAMAGE IN CANTON ACCIDENT

\section{Summary of Injuries/Fatalities in Canton Accident}

There were about 300 passengers in the six passenger cars. About 150 passengers incurred minor injuries, which included minor broken bones, broken noses, neck and back sprains, contusions, lacerations, and concussions. These are all classified as AIS 1 injuries.

\section{Summary of Injury Measurements in M-Style and Walkover Seat Sled Tests}

The M-Style seat is a relatively compliant seat, which was evidenced by fairly low injury loads measured in the ATDs. The HIC measurements in five of the six ATDs were below 360 and classified as AIS 1 injuries. The highest HIC measured was 738, which is classified as an AIS 2 injury. All 3ms chest deceleration measurements were below 35 Gs and classified as AIS 1 injuries. All axial femur load measurements were below $900 \mathrm{lbs}$. and classified as AIS 1 injuries. Only one injury measurement exceeded the injury criterion, the upper neck flexion/extension moment, which occurred in the 5th-percentile female ATD. The criterion limit of $+70 \mathrm{ft}-\mathrm{lbs}$ was exceeded by only $2 \mathrm{ft}-\mathrm{lbs}$.

The deformation and rotation of the Walkover seat back helped keep the measured injury loads to a minimum in the Walkover seat sled tests. All HIC, 3ms chest decelerations, and axial femur loads were low in the tests of the Walkover seats, and classified as AIS 1 injuries.

The injury measurements in the Walkover and M-Style seat sled tests are consistent with the injuries observed in the Canton accident.

\section{DISCUSSION}

Accident outcomes have been compared to seat test results to demonstrate the similarities and differences. This comparison has focused on the seat/table damage, injuries, and acceleration-time history.

The acceleration-time history is influenced principally by the mass, velocity, and force-crush behavior of the colliding equipment. It can be difficult to assess the severity of the measured or calculated acceleration-time history due to significant high-frequency oscillations. The SIV plot concept was developed to more easily compare the relative velocity and displacement associated with different acceleration-time histories. SIV is an indicator of collision severity, but it is not a reliable predictor of interior crashworthiness.

Structural crashworthiness can be evaluated in terms of the amount of occupied volume that is crushed. Car crush can be minimized by incorporating crush zones in unoccupied areas of the train, combined with a strong carbody structure to preserve the occupied areas of the train. However, an exceedingly strong occupied volume can negatively affect the interior crashworthiness by causing significant carbody decelerations.

The wide range of equipment types, operating conditions, and potential collision scenarios produce a wide range of possible collision crash pulses. System safety strategies can help to minimize the likelihood of particular kinds of accidents, such as a dedicated right-of-way to prevent grade crossing accidents. CEM equipment can help to minimize the crush in occupied areas of the train and minimize carbody decelerations. Interior fixtures designed to deform under load while remaining attached can minimize forces experienced by occupants during secondary impacts.

A goal of standards and regulations is to provide a minimum level of safety. Many different strategies can be used to provide equivalent safety. Given the conventional speed operating practices in the U.S., the APTA Seat Standard provides an acceptable level of protection against secondary impact injuries.

\section{CONCLUSIONS}

The interior crashworthiness observations from three passenger train accidents have been compared with the injury measurements and seat damage from sled tests. The sled tests were conducted on the same type of seats that were in the respective accidents. The crash pulses, i.e., acceleration time histories, from the accidents and the sled tests were numerically integrated to develop plots of secondary impact velocity.

The SIV curves associated with the Chatsworth accident are similar or somewhat more severe than the SIV curve associated with the $8 \mathrm{G}$ crash pulse used in most of the sled

This material is declared a work of the U.S. Government and is not subject to copyright protection in the United States. Approved for public release; distribution is unlimited. 
tests. The resulting seat damage observed in the Chatsworth accident was similar or more severe than the damage observed in the sled tests. The injuries observed in the accident were generally more severe than those measured in the sled tests. The lack of abdominal instrumentation for ATDs contributed to the underestimate of injury in the tests. To adequately capture injuries caused by table impacts in testing, additional ATD instrumentation is necessary. Abdominal injury due to table impacts in accidents has led to the development of a draft APTA safety standard for workstation tables.

The SIV curves associated with the Chicago and Canton accidents are somewhat less severe than the curve associated with the $8 \mathrm{G}$ pulse. Correspondingly, the seat damage and injuries observed in these accidents were somewhat less than was measured in the sled tests of the Amtrak traditional, MStyle, and Walkover seats. The M-Style seats in the leading car had been retrofitted with seats that met the APTA Seat Standard. The M-Style seats in the other cars did not meet the Seat Standard, nor were they required to, based on procurement dates. The M-Style seats that did not meet the standard experienced more severe damage than the M-Style seats that did meet the standard.

These results indicate that the $8 \mathrm{G}$ pulse is consistent with the accident severity for collisions involving conventional equipment in which the structural integrity of one or more cars has been compromised. Seats designed to an $8 \mathrm{G}$ crash pulse are expected to remain attached in such a collision. The APTA Seat Standard requires seats to compartmentalize ATDs in such a collision, and requires that the measured injury criteria will remain below specified levels. While there is no minimum required seat back height, accident observations and test data have demonstrated that taller seat backs provide increased likelihood of occupant compartmentalization, as well as additional head/neck support that can minimize head/neck injuries.

The $8 \mathrm{G}$ pulse is associated with a moderately severe collision. There is some factor of safety inherent in this pulse, which provides occupant protection even after the integrity has been compromised in the car structure. The $8 \mathrm{G}$ pulse provides a level of occupant protection consistent with other modes of public transportation under such conditions.

\section{ACKNOWLEDGMENTS}

This work was performed as part of the Equipment Safety Research Program sponsored by the FRA's Office of Research and Development. The authors would like to thank Jo Strang, Associate Administrator for Railroad Safety/Chief Safety Officer, FRA, and Kevin Kesler, Division Chief, Equipment and Operating Practices Research Division, Office of Research and Development, FRA, for supporting the work of the forensic accident investigation team; Jeff Gordon, Program Manager, Equipment and Operating Practices Research Division, Office of Research and Development, FRA, and Benjamin Perlman, Volpe Center, for technical advice and paper editing; Kari Jacobsen, Volpe Center, for collision dynamics modeling results; and Patricia Llana, Volpe Center, for information related to the accident investigations. The authors would like to thank the Forensic Passenger Accident Investigation Team: Peter Lapre, Charles Whalen, Jennifer Schuster, Mark Sandler, and Phillip Marceau, all of the FRA, for their work investigating train accidents described in this paper.

\section{REFERENCES}

[1]. APTA SS-C\&S-016-99, Standard for Passenger Seats in Passenger Rail Cars, The American Public Transportation Association, Washington, DC.

[2]. National Transportation Safety Board, "Collision of Metrolink Train 111 with Union Pacific Train LOF65-12 Chatsworth, California September 12, 2008," NTSB Railroad Accident Report, PB2010-916301, NTSB/RAR10/01, January, 2010.

[3]. National Transportation Safety Board, "Collision of Amtrak Passenger Train 371 and Norfolk Southern Railway Company Freight Train 23M , Chicago, Illinois, November 30, 2007," NTSB Railroad Accident Report, PB2009-916301, NTSB/RAR-09/01, March, 2009.

[4]. Llana, P., and Tyrell, D., "Preliminary Reconstruction of the November 30, 2007 Chicago, IL Rail Collision," 2011 ASME/IEEE Joint Rail Conference, JRC2011-56103.

[5]. Tyrell, D., Jacobsen, K., and Llana, P., "Observed Equipment Damage and Analytically Estimated Car Decelerations in Selected Passenger Train Accidents," ASME JRC 2012, JRC2012-74118.

[6]. Priante, M. "Review of a Single Car Test of Multi-Level Passenger Equipment" American Society of Mechanical Engineers, Paper No. JRC2008-63053, April 2008.

[7]. Tyrell, D.C., Severson, K.J., Marquis, B.J., "Train Crashworthiness Design for Occupant Survivability," American Society of Mechanical Engineers, AMD-Vol. 210, BED-Vol. 30, pp. 59-74, 1995.

[8]. VanIngen-Dunn, C., "Commuter Rail Seat Testing and Analysis of Facing Seats," US Department of Transportation, DOT/FRA/ORD-03/06, December 2003.

[9]. Code of Federal Regulations, Title 49, Part 571, Section 208, Occupant Crash Protection, October 1, 2002.

[10]. Severson, K., Perlman, B.A., Stringfellow, R. "QuasiStatic and Dynamic Sled Testing of Prototype Commuter Rail Passenger Seats" American Society of Mechanical Engineers, Paper No. JRC2008-63051, April 2008.

[11]. Tyrell, D., Severson, K.J., "Crashworthiness Testing of Amtrak's Traditional Coach Seat", US Department of Transportation, DOT/FRA/ORD-96/08, October 1996.

[12]. VanIngen-Dunn, C., Manning, J., "Commuter Rail Seat Testing and Analysis," US Department of Transportation, DOT/FRA/ORD-01/06, July 2002.

This material is declared a work of the U.S. Government and is not subject to copyright protection in the United States. Approved for public release; distribution is unlimited. 